\title{
A CONSTRUÇÃO DO SUJEITO NARRADOR: PENSAMENTO DISCURSIVO NA ETAPA PERSONALISTA
}

\author{
Vivian Hamann Smith \\ Tânia Mara Sperb\#
}

\begin{abstract}
RESUMO. A narrativa é uma forma de pensamento discursivo que permite à criança pré-escolar construir progressivamente um sentido de si própria, enquanto se situa num mundo de relações e práticas sociais. Neste trabalho, conceitos de Wallon sobre o desenvolvimento e a linguagem na etapa personalista são utilizados como base teórica para discutir as contribuições de estudos sociointeracionistas contemporâneos sobre narrativas. O estudo do desenvolvimento da narrativa possibilita acompanhar o processo de incorporação, pela criança, de elementos dos outros e da cultura, ao mesmo tempo em que ela se diferencia como indivíduo, colocando-se como narradora e avaliando aquilo que conta. A apropriação de formas convencionais de contar histórias contribui para a organização e sofisticação do pensamento discursivo e da imaginação criadora, possibilitando que a criança desenvolva recursos cognitivos e afetivos para interagir com um mundo multidimensional, complexo e em constante processo de mudança.
\end{abstract}

Palavras-chave: narrativa, teoria de Wallon, construção do eu.

\section{THE CONSTRUCTION OF THE NARRATOR SUBJECT: DISCOURSIVE THOUGHT IN THE PERSONALIST STAGE}

\begin{abstract}
Narrative is a kind of discoursive thought that allows the preschooler child to progressively construct a sense of self, while she situates herself in a world of relationships and social practices. In this paper, Wallon's concepts on development and language in the personalist stage are taken as a theoretical framework to discuss contributions of contemporary sociointeractionists studies on narrative. The study of narrative development permits that children's process of incorporation of others and cultural elements may be followed, at the same time as they differentiate themselves as individuals who narrate and evaluate what is told. The appropriation of conventional forms of telling stories contributes to the discoursive thought organization and sophistication and of creative imagination. This appropriation enables children to develop cognitive and affective resources to interact with a multidimensional world that is complex and changeable.
\end{abstract}

Key words: Narrative, Wallon's theory, self- construction.

\section{LA CONSTRUCCIÓN DEL SUJETO NARRADOR: PENSAMIENTO DISCURSIVO EN LA ETAPA PERSONALISTA}

RESUMEN. La narrativa es una forma de pensamiento discursivo que permite al niño preescolar construir progresivamente un sentido de sí propio mientras se sitúa en un mundo de relaciones y prácticas sociales. En este trabajo conceptos de Wallon sobre el desarrollo y el lenguaje en la etapa personalista son utilizados como base teórica para discutir las contribuciones de estudios sociointeraccionistas contemporáneos sobre narrativas. El estudio del desarrollo de la narrativa posibilita acompañar el proceso de incorporación, por el niño, de elementos de los otros y de la cultura, al mismo tiempo en que él se diferencia como individuo, colocándose como narrador y evaluando lo que cuenta. La apropriación de formas convencionales de contar historias contribuye para la organización y sofisticación del pensamiento discursivo y de la imaginación creadora, posibilitándole al niño desarrollar recursos cognitivos y afectivos para interaccionar con un mundo multidimensional, complejo y en constante proceso de cambio.

Palabras-clave: narrativa, teoría de Wallon, construcción del yo.

* Doutora em Psicologia do Desenvolvimento. Professora Adjunto da Faculdade Porto Alegrense de Educação Ciências e Letras, FAPA-RS.

\# Doutora em Psicologia do Desenvolvimento. Professora da Universidade Federal do Rio Grande do Sul. 
A transição que a criança pequena realiza de uma consciência de mundo e de si mesma, impregnada de confusão, de afetividade e fantasia, para uma visão mais realística e lógica, é gradual e pode envolver impasses e conflitos. Vai se esboçando para ela a consciência da finitude, da diversidade de valores e estilos pessoais, das diferenças sociais e étnicas, das exigências e responsabilidades ligadas ao crescimento. Dependendo do apoio de pessoas significativas, dos recursos que a criança encontre à sua disposição e também de uma certa decisão dela em ir adiante e crescer, tais impasses podem gerar dificuldades que serão mais tarde expressas em problemas de aprendizagem, de aceitação e adaptação a regras, de motivação para conhecer e lidar com a vida e seus dramas inevitáveis. Qual o lugar e papel da linguagem nesse processo?

Perspectivas sociointeracionistas têm destacado a importância da apropriação da linguagem para a organização e reorganização de significados, bem como a amplitude desta tarefa para a criança pequena. Ao tentar explicar as coisas e narrá-las, a criança tem de lidar ao mesmo tempo com a multiplicidade e complexidade (da experiência, da cultura e da língua) e manter um sentido mais ou menos integrado e estável de si mesma. Este sentido de si mesma vai sendo construído a partir das diferenciações e identificações que a criança vai estabelecendo em relação às pessoas disponíveis, os seus “outros", o que ocorre em grande parte na brincadeira de faz-de-conta e na linguagem oral, no contexto das interações cotidianas com adultos e outras crianças. Envolvida tanto nas brincadeiras infantis como nas conversas, a narrativa tem sido considerada, atualmente, por autores como Bruner (1997, 1998), Dunn (1988) e Nelson (2000), como um instrumento privilegiado e precoce de organização desta experiência multidimensional, proporcionando-lhe sentido e continuidade. Ela abarca os planos subjetivo e interpessoal e as contínuas negociações de significados e padrões culturais, além da temporalidade e da espacialidade. Permite também a elaboração de temas complexos e dramáticos da experiência humana, não necessariamente resolvendo os dramas, mas conferindo aos acontecimentos um sentido e uma ordem temporal que podem ser organizados e reorganizados (Ricoeur, 1980). Além disso, de acordo com pesquisadores como Heath (s.d.) e Griffin (2004), por ajudar a criança a falar sobre coisas não imediatas e mais distantes, a narrativa favorece a descontextualização e a abstração da linguagem, aspectos envolvidos em habilidades ligadas ao letramento e a toda a futura escolarização.
Pretende-se neste trabalho promover um encontro entre duas vertentes de contribuições para a teoria e pesquisa em psicologia: a teoria walloniana sobre o desenvolvimento da pessoa completa, com foco na idade pré-escolar, e os estudos contemporâneos sobre narrativa.

A abordagem de Wallon (1934/1995, 1941/2000, 1942/1947, 1945/1989) permite compreender a construção dinâmica e conflitiva do sujeito psicológico nas dimensões psicomotora, afetiva e cognitiva, a partir da imersão em seu ambiente sociocultural, incorporando aspectos dos seus "outros" e se diferenciando progressivamente como indivíduo. A apropriação da linguagem tem papel objetivante, estabilizador e organizador em todo este processo, possibilitando o desenvolvimento do pensamento discursivo.

Os estudos contemporâneos sobre narrativa emergem a partir dos anos 1980, com a convergência entre contribuições de pensadores provenientes de vários campos do conhecimento, criando o campo da narratologia. É no contexto das contribuições de abordagens psicológicas sociointeracionistas e da sociolingüística que será situada a possível articulação dos estudos sobre narrativa com a teoria de desenvolvimento de Wallon.

A abordagem sociolingüística mostra a narrativa como texto produzido em interação com um contexto, dirigido a interlocutores, construído em colaboração com eles nos seus aspectos estruturais e avaliativos (Fivush \& Haden, 1997; McCabe, 1996; UmikerSebeok, 1979) e profundamente influenciado por fatores culturais (Heath, s.d.; Melzi, 2000; Michaels, 1986; Shiro, 2003). Entretanto, parece faltar uma estrutura conceitual fortemente sustentada sobre uma epistemologia sociointeracionista, que descreva as várias dimensões do desenvolvimento, para integrar e articular todo este corpo de idéias e dados de pesquisa. Isso talvez possa ser encontrado na teoria walloniana. Wallon (1942/1947, 1945/1989) investigou o desenvolvimento do pensamento discursivo tomando como parâmetro a lógica categorial e considerando as narrativas infantis ora como formas lúdicas, ora como maneiras precárias e provisórias de explicar relações temporais e causais, mas sempre do ponto de vista das insuficiências de um pensamento ainda instável e confuso. Embora tenha chegado a considerar a possibilidade de que o pensamento da criança préescolar seja narrativo (Wallon, 1941/2000), não chegou a desenvolver esta idéia em investigações, nem supôs um desenvolvimento para este tipo específico de pensamento discursivo. É possível considerar que os estudos sobre narrativa contribuam para o 
entendimento tanto dos processos de diferenciação do indivíduo como de incorporação de aspectos do outro e da cultura. Estes processos são expressos e constituídos pela linguagem, e podem ser especialmente observados em sua gênese na criança pré-escolar, como tem sido demonstrado em estudos da sociolingüística (Perroni, 1992; Costa Silva, 2000).

Para organizar o diálogo entre a perspectiva walloniana e a teoria e pesquisa sobre narrativa, serão definidos dois diferentes planos envolvidos na construção narrativa e no desenvolvimento desta habilidade pela criança: o plano da realidade social e suas convenções e o plano da construção do conhecimento. Permeando e integrando os dois está a construção da pessoa que pensa, sente e se expressa nas suas interações.

Serão focalizados inicialmente os conceitos de Wallon sobre linguagem e o pensamento discursivo.

\section{LINGUAGEM E A GÊNESE SOCIAL DO PENSAMENTO DISCURSIVO}

Wallon (1942/1947) enfatiza a origem social da linguagem, suas representações e relações, formas e significações. A sociedade é vista como a matriz indispensável do pensamento discursivo individual, definido como a linguagem enunciada ou interior. Este tipo de pensamento é expresso pela linguagem e moldado por ela (Wallon, 1945/1989). Possibilita o uso da linguagem de forma livre de circunstâncias ou atos, utilizando-a para evocar o ausente, expressar idéias, conhecimento, estabelecendo um encadeamento de imagens, recordações, conceitos.

Há um longo processo de apropriação entre linguagem e objeto, palavras e coisas, em que a assimilação imitativa das formas e significações precede o seu emprego correto e pessoal pelo indivíduo. “(...) o próprio da linguagem humana é ser uma criação coletiva à qual cada um deve adaptar suas criações lingüísticas" (Wallon, 1942/1947, p.195).

Para Wallon (1942/1947), o grande salto qualitativo que possibilita a aquisição da linguagem ocorre a partir da imitação diferida e da representação, em torno dos dois anos de idade. Ambas se configuram conforme o modelo das coisas presentes no meio que envolve a criança, reduzindo as impressões dispersas, proporcionando objetividade e sucessão (de atos ou de representações).

A linguagem é o instrumento que possibilita o desenvolvimento de relações entre as representações, o que permite a sua organização em seqüência, o desdobramento das idéias, eventos e situações no tempo. Instrumentos simbólicos como imagens, sinais ou palavras atuam como suportes ou substitutos para que a criança supere a tendência à perseveração, instabilidade e confusão do ato mental e consiga confrontar o ausente a que procura se referir com as impressões presentes.

Símbolos e signos são instrumentos convencionais de significação; há desdobramento, separação entre eles e o que significam, com a sobreposição da representação ao real. Opõem significante e significado de diferentes maneiras: o símbolo é um objeto substituto de outras realidades, ainda concreto, mas com função representativa. $\mathrm{O}$ signo dá acesso à verdadeira representação, pois pode não ter relação alguma com o objeto representado. É um símbolo depurado a ponto de não mais pertencer ao mundo das coisas, possuindo independência em relação ao objeto que substitui.

Para explicar a apropriação de símbolos e signos culturais pela criança pequena, Wallon (1942/1947) introduz o conceito de simulacro como condição necessária à representação, numa continuidade da imitação no plano motor. Simulacro é a simulação de características do referente através de gestos ou posturas, de forma que a criança faz uso de um objeto pela mímica, sem que ele esteja presente. Segundo Vasconcellos (1996), pelo simulacro a imitação se desenvolve em ato, expressando a compreensão, por parte da criança, da cena, do drama, ainda não recitados, mas gestuados. Mesmo depois que a criança já começa a relatar acontecimentos, esta forma de mímica ainda se faz presente nos gestos que evocam presenças e circunstâncias, e nas brincadeiras infantis. Pode-se por isso pensar o simulacro da criança pequena como a gênese comum do brincar e da narrativa.

De modo semelhante a Wallon, as perspectivas sociointeracionistas contemporâneas também enfatizam a origem mimética e sociocultural da linguagem e da narrativa.

\section{NARRATIVA E CULTURA}

De forma abrangente, a narrativa pode ser definida como uma sucessão de proposições (ou imagens, gestos, no caso de linguagens não-verbais) indicativa de que algo aconteceu. Para Bruner (1998), a narrativa é um modo de pensamento que pode se expressar discursivamente, organizando-se numa história. Esta envolve personagens (com suas intenções e ações), circunstâncias e conseqüências num deslocamento no tempo, criando um enredo. Esta perspectiva temporal diferencia uma história do discurso descritivo ou do explanatório, além do fato de 
que a narrativa não tem um compromisso estrito com a veracidade ou com a coerência do raciocínio, e sim, com a verossimilhança. O modo narrativo organiza a experiência contando uma história que faça sentido. Fivush e Haden (1997) defendem que é somente através da linguagem que se pode desenvolver a habilidade de narrar sobre a experiência, reconfigurando numa trama a sua ordem de sucessão, para poder compreendê-la.

A utilização de histórias orais é uma prática comum às sociedades de todas as épocas e lugares, de forma ritualizada ou no cotidiano, e atende a múltiplas funções essenciais à vida numa cultura: a comunicação, a explicação de motivações para comportamentos e de causas para as coisas, a persuasão, a criação de versões para acontecimentos, o entretenimento, a construção de mundos e situações possíveis. Bruner (2000) ressalta o poder das histórias para gerar um self particular numa cultura particular, proporcionando uma espécie de mapa de mundos possíveis nos quais a ação, o pensamento e a autodefinição sejam situados.

Cada história em particular remete a tipos mais genéricos, que têm sido tradicionalmente considerados como universais nos temas que abordam e até mesmo na sua estrutura (Vieira, 2001). Entretanto, as formas e estilos da narrativa são muito diversificados em diferentes culturas, possuindo um caráter histórico e variável. Há uma relação dialética entre narrativa e cultura, já que as histórias fazem a mediação, expressam e definem a cultura, mas a cultura também define a narrativa (Brockmeier \& Harré, 2003). Num artigo recente, Feldman (2005) ressalta o caráter convencional e mimético da narrativa e do brincar, já que ambos partem da imitação de uma experiência mediada pelos outros indivíduos e a cultura, utilizam representações convencionadas mesmo para criar mundos possíveis, e necessitam da interpretação de outras pessoas, o que depende também de certas convenções. Bruner (2000) diz que gêneros são formas culturalmente especializadas de vislumbrar a condição humana e comunicá-la. Assim, utilizamos de forma familiar e espontânea o repertório de contar histórias típico da nossa linguagem e cultura desde a infância, podendo estranhar ou rejeitar maneiras "estranhas" de contar as coisas, que nos pareçam absurdas, confusas ou lingüisticamente "deficientes" (Soares, 2002). Isso tem dificultado a compreensão, investigação e promoção de formas não hegemônicas de estrutura e performance narrativa, diferentes de padrões dominantes relacionados a aspectos étnicos ou socioeconômicos, conforme mostram Heath (s.d.), McCabe (1996), Melzi (2000), Michaels (1986), Soares (2002) e Sawaya (2001), que se dedicaram a estudar estas diferentes características nas interações e produções lingüísticas e narrativas.

Embora ressaltem as diferenças e barreiras interculturais, as abordagens sociolingüísticas da narrativa não costumam focalizar o caráter descontínuo e ambivalente do processo de apropriação cultural, de autodefinição e conhecimento do real pela criança, como faz Wallon.

\section{CONSTRUÇÃO DO "EU PSICOLÓGICO” E O PENSAMENTO DISCURSIVO SINCRÉTICO}

Para Wallon, as aquisições do desenvolvimento humano consistem em processos descontínuos e conflitivos. A aquisição da linguagem é um exemplo disso, podendo atrair ou repelir a criança em diferentes momentos, gerando incertezas e hesitações. A linguagem coloca entre a criança e seus desejos, e entre ela e os outros, um obstáculo e instrumento que se sentirá tentada a evitar ou a dominar (Wallon, 1941/2000).

Analisando a relação que Wallon faz entre a imitação e a construção da linguagem falada, Vasconcellos (1996) ressalta a profunda modificação na própria atividade de imitação, que se transforma progressivamente numa imitação inteligente ou semiótica. A criança vai construindo o significado da linguagem, utilizando a imitação diferida como instrumento de expressão, de identificação e diferenciação em relação aos outros, e também como instrumento de construção de significado. A linguagem da criança vai se tornando mais expressiva e superando a própria imitação, para desenvolver o pensamento discursivo. Entre os dois e os três anos mais ou menos, a criança produz diálogos consigo mesma, quando aparecem múltiplas "vozes", o que manifesta, para Wallon (1941/2000), o sincretismo da sua personalidade ainda indistinta em relação aos seus "outros" e às situações de que participa. Tais diálogos diminuem e até desaparecem após a oposição característica da criança no início da etapa personalista, quando ela passa a falar em seu próprio nome, tentando marcar seu próprio ponto de vista. A partir daí, a linguagem vai ajudando a criança a constituir um sentido mais forte de si mesma, sendo usada nas crises de oposição e nos jogos de alternância. O domínio do pronome possessivo (meu, minha) e o uso do pronome 
pessoal "eu" faz com que as idéias atinjam o sentimento de propriedade das coisas, no caminho da afirmação de si, tanto pela oposição, ridicularização e negação das coisas do outro, como pela recriação da fala do outro (Vasconcellos, 1996).

A construção de um senso mais estável de si mesmo como um ser psicológico é, para Wallon (1934/1995), a tarefa central do desenvolvimento na idade pré-escolar. Ele define esta etapa como a de uma crise personalista, em que a criança tem de fazer um movimento de diferenciação em relação às outras pessoas significativas como um "eu" que sente, pensa e quer, mas necessita ao mesmo tempo do apoio e afeto, da referência e reconhecimento dos seus. Dessa crise decorre uma tonalidade fortemente afetiva, turbulenta e subjetiva na atividade da criança. A imitação do outro é necessária para a criança, mas provoca ambivalência, envolvendo tanto a admiração amorosa como o desejo de substituir o outro, superá-lo e não depender dele. Mais tarde, um ou outro destes aspectos pode se tornar predominante. Esta ambivalência dinamiza a diferenciação do "eu", e a imitação vai se integrando ao comportamento da criança como um de seus meios. Em torno dos quatro anos, espera-se que a criança tenha superado o comportamento negativista, marcado pela oposição, desenvolvendo então uma progressiva capacidade de sedução e persuasão do outro através de uma conduta exibicionista e de formas verbais de negociação. A partir dos seis anos, aproximadamente, a imitação vai se tornando raciocinada e reflexiva. Os interesses diferidos substituem gradualmente os interesses imediatos (Wallon, 1941/2000, 1942/1947).

É neste contexto que a criança vai construindo seu pensamento discursivo, tanto para interagir com as pessoas como para compreender o mundo e a si mesma. Como já referido anteriormente, para Wallon (1945/1989), o pensamento discursivo se expressa e é moldado pela linguagem, tornando-se uma linguagem enunciada e simultaneamente interior. $\mathrm{O}$ autor investigou $\mathrm{o}$ pensamento discursivo de crianças a partir dos cinco anos, quando estas geralmente já se apropriaram do sistema lingüístico do seu ambiente cultural e começam progressivamente a realizar um trabalho mental com palavras, formulando hipóteses explicativas sobre as coisas que experimentam. Isso envolve um afastamento da sua experiência concreta para definir as coisas e estabelecer relações entre elas no plano da representação.
Entretanto, o autor ressalta que esta nova possibilidade traz ao mesmo tempo dificuldades que estabelecem uma descontinuidade no desenvolvimento infantil. De um lado, podemos considerar dificuldades cuja fonte é a própria criança: além da tonalidade afetiva e subjetiva característica da etapa personalista, o cérebro infantil encontra-se ainda imaturo para coordenar seus conceitos e idéias e organizá-los em diferentes planos lógicos. Por outro lado, as explicações da criança são dificultadas por conflitos decorrentes do próprio objeto a ser explicado: pela complexidade do real, do qual a criança já tem um conhecimento prático através da sua experiência, pelas contradições geradas pela própria linguagem, em função da multiplicidade de sentido e uso das palavras, e pela necessidade de incluir na sua compreensão as informações e práticas fornecidas pela tradição cultural, tanto de natureza mítica como científica. Dantas (1990) sintetiza o impasse, situando as tentativas de explicação da criança entre dois oceanos moventes: o das coisas e o das idéias que estão se formando. Pode-se acrescentar a isso a pessoa que está se construindo. Wallon (1945/1989) denomina o pensamento discursivo da criança desta idade como sincrético ou précategorial, caracterizado essencialmente pela instabilidade e contradição, pela confusão e a colocação de uma realidade multidimensional num único plano.

A progressiva estruturação narrativa não foi considerada por Wallon (1945/1989). Para o autor, a organização do pensamento discursivo parte de uma estrutura binária que compõe em pares os objetos mentais, estabelecendo dualidades. O pensamento categorial, mais coerente e diferenciado, deve colocar a experiência em perspectiva, organizando os temas em planos distintos: do particular ao geral, da consequiência ao princípio, do fato à causa, possibilitando uma maior análise e compreensão dos eventos. Esta diferenciação conceitual envolve, para Wallon, duas tarefas: definir as coisas e explicá-las. Definir consiste em caracterizar um objeto por propriedades que o distinguem dos demais. Explicar é relacionar, religar, integrar, situando o objeto dentro de uma rede de vínculos nítidos. O objeto é integrado num contexto no qual perde sua identidade fechada e pode ser conectado a outros objetos. Tal evolução envolve profundamente a afetividade da criança: para poder representar e conceituar as coisas, a criança deve reduzir gradualmente sua união com elas. 
Wallon (1945/1989) verificou a persistência do sincretismo para definir e explicar até em torno de nove anos, mas não fixa uma idade ou momento de superação das contradições conceituais. Isto parece depender mais da complexidade do tema abordado e da afetividade envolvida do que da idade. Mesmo no adulto reaparecem as manifestações de sincretismo quando predomina a afetividade, focalizando a atenção do indivíduo em sua subjetividade. Aliás, atividades artísticas e mesmo científicas exigem em dado momento a retomada de uma visão global e indistinta e da combinação, livre de lógica, de novas possibilidades.

Bastos (2003) ressalta a necessidade de estudos que investiguem melhor o papel da inteligência na etapa personalista, para compreender o desenvolvimento do pensamento discursivo da criança sobre si mesma e suas relações com os outros.

Wallon entende a narrativa infantil como uma manifestação do pensamento sincrético.

\section{AS INSUFICIÊNCIAS DO NARRAR}

Wallon (1941/2000, 1942/1947, 1945/1989) refere-se à narrativa da criança em termos da sua incapacidade explicativa. Não podendo explicar coerentemente, a criança conta coisas e fabula. Mas o narrar da criança pequena é também descrito por ele como instável e precário, impregnado pela percepção e afetividade. Segundo o autor, a criança conta algo representando gestualmente, com suas atitudes e expressões, o que está recordando ou imaginando, apresentando e distribuindo os objetos e personagens que evoca. Tende a relatar tudo o que é evocado, como se para lembrar tivesse que enunciar todas as circunstâncias concretas, o que muitas vezes traz um peso que faz com que o fio da narrativa se rompa e se perca (Wallon, 1941/2000). Por outro lado, ainda indiferenciada das situações que conta, a criança pode modificá-las totalmente a partir da sua sensibilidade. Freqüentemente, a criança apenas enumera temas de forma seqüencial, sem estabelecer relações de temporalidade ou causalidade. As proposições são ligadas conforme a ocasião, o desejo ou inspiração do momento, os esquemas habituais ou recentes da criança, não constituindo uma verdadeira unidade de realidade ou de sentido. Hoje, estudos sobre narrativa mostram estas características do narrar infantil como a expressão de momentos do processo de construção deste modo discursivo (Fivush \& Haden, 1997; Ilgaz \& Aksu-Koç, 2005; McCabe,
1996; Umiker-Sebeok, 1979), dentro do qual a criança vai organizando gradativamente relações mais lógicas que envolvam várias dimensões (Bruner, 1997).

Outra referência às histórias que as crianças contam é encontrada quando Wallon (1945/1989) se refere à fabulação. Nesta, a criança faz uma digressão, encadeando temas com fluência e espontaneidade, inventando situações. É uma espécie de fuga de idéias ou "colcha de retalhos" (Dantas, 1990, p. 53) que preenche as lacunas do conhecimento da criança, dando a ela a impressão de ter resolvido todas as dificuldades e contradições. A fabulação, para Wallon (1945/1989), tem um sentido lúdico de exercício funcional, que cria uma zona intermediária livre das exigências lógicas, onde a verdade e a fantasia não se opõem, mas permanecem confundidas em uma espécie de combinação funcional. Possivelmente em função da concepção centrada no discurso descritivo e explanatório que dominava o estudo da inteligência na sua época, o autor considera a fabulação como um estratagema provisório para lidar com a insuficiência lógica, ignorando-a como instrumento intelectual que possa se desenvolver em si mesmo. "Estas histórias ficam à margem da realidade. Não servem de explicação. É um mundo em que a criança se refugia, longe das curiosidades ou das burlas do adulto. É um jogo" (Wallon, 1942/1947, p. 108).

Entretanto, é neste conceito walloniano de jogo como combinação funcional de realidade e fantasia que pode estar situada a importância da narrativa para o desenvolvimento, tanto do pensamento discursivo categorial quanto do sincrético. Narrar permite abordar uma complexa realidade simbólica e relacional através de possibilidades, e não apenas da necessidade lógica e empírica.

\section{A CONSTRUÇÃO DA NARRATIVA E DO SUJEITO NARRADOR}

A narrativa tem sido considerada como um instrumento precoce e fundamental com que organizamos discursivamente nossa experiência, como indivíduos inseridos numa realidade complexa e predominantemente cultural. Escutando e contando histórias vamos construindo um sentido de mundo e de nós mesmos, estabelecendo uma continuidade entre os eventos, numa perspectiva simultânea da ação e da intencionalidade de pessoas situadas num cenário físico e social. 
Conforme Bruner (1991, 2000), narrar possibilita o estabelecimento de relações não restritas à causalidade lógica, incluindo a causalidade psicológica ou intencionalidade na explicação dos eventos e situações; proporciona também o trabalho discursivo com o particular e o geral, simultaneamente; permite o estabelecimento de uma ordem temporal ou seqüência de eventos, oferecendo também a possibilidade de criar relações entre parte e todo de uma maneira dialética e flexível, favorecendo o desenvolvimento da capacidade de interpretação hermenêutica.

Nelson (2000) destaca a importância do auxílio das pessoas significativas para que a criança construa o que chama de self na cultura ${ }^{l}$, para que possa compreender um complexo mundo social formado por pessoas interagindo em realidades múltiplas visíveis e invisíveis, ao mesmo tempo em que procura identificar em si mesma uma unidade psíquica que permaneça constante, um self que era o mesmo no passado e que pode ser projetado no futuro. Embora o conflito afetivo envolvido nesta diferenciação não chegue a ser abordado, pode-se reconhecer neste conceito de Nelson uma semelhança com a idéia walloniana de construção de um "eu psíquico", também a partir da imersão da criança numa sociabilidade sincrética (Wallon, 1934/1995). Ouvindo histórias sobre diferentes pessoas, com distintas perspectivas sobre o mundo, emoções e intenções, em diferentes lugares e épocas, a criança vai tomando consciência sobre seu próprio ponto de vista e existência situada num contexto específico, que inclui lugares diversos, que tem uma história desenvolvida através do tempo, antes que ela possa lembrar, e que se projeta para o futuro. É durante os anos pré-escolares que as crianças começam a construir suas histórias pessoais, em colaboração com os outros - pais, professores, pares - com quem são compartilhadas suas experiências e seu mundo cultural.

Como ocorre a evolução da narrativa, que aspectos desta habilidade se desenvolvem, como melhor acessar estes diferentes aspectos e qual o tipo de apoio educacional desejável para que este desenvolvimento ocorra são questões ainda abertas e controvertidas. Grande parte dos estudos encontrados focaliza o desenvolvimento da habilidade narrativa de crianças brancas de classe média, em centros urbanos, em sociedades que estimulam um padrão linear de estrutura narrativa (início-meio-fim), voltado para a descontextualização do discurso e a resolução de

Tradução livre de encultured self. problemas. Como modelo de racionalidade vigente, tal padrão é coerente com habilidades discursivas exigidas pela escolarização, o que traz vantagens para o letramento de crianças familiarizadas com essas formas de contar histórias e pode gerar dificuldades para crianças socializadas em diferentes modelos narrativos (Heath, s.d.; Michaels, 1986; Sperb \& Smith, 2005).

Como se dá então a evolução das narrativas das crianças no padrão desejável à escolarização, descrito pela literatura? Pode-se pensar que este padrão propicia o desenvolvimento da lógica categorial focalizada por Wallon, uma vez que envolve o aumento na organização, na coesão e complexidade da articulação entre as proposições, e na sofisticação e explicitação das referências e da avaliação nas histórias contadas ou recontadas pela criança.

Dunn (1988) mostra que crianças pequenas, antes dos três anos, além de já demonstrarem um vivo interesse por histórias infantis e pelos relatos dos outros sobre "o que aconteceu", já começam a brincar narrativamente, tanto sozinhas como com outras pessoas.

As narrativas de experiências pessoais geralmente se desenvolvem mais precocemente, no contexto das conversas cotidianas (Peterson, 1990; Shiro, 2003), enumerando eventos rotineiros, depois introduzindo acontecimentos excepcionais e estabelecendo seqüencialidade. As narrativas pessoais parecem ser mais sofisticadas quando são relatadas experiências não compartilhadas com interlocutor adulto (McCabe, 1996). Entre dois e três anos, a criança começa a usar referência espacial, especialmente quando se refere a um contexto diferente do presente. Este tipo de orientação aparece antes das referências de tempo, que envolvem múltiplas dimensões e são mais abstratas. Peterson (1990) constatou que o "eu" era a principal referência das histórias, ou então um genérico "nós", sendo também mencionados nomes sem especificação do contexto. Este dado é coerente com a ênfase personalista desta etapa do desenvolvimento, segundo Wallon (1934/1995). Além disso, embora os elementos de orientação ainda apareçam de forma irregular e confusa, as crianças já manifestam formas de avaliação do que contam: aos dois anos, isso pode ser visto mais nos gestos e expressões faciais e vocais (Fivush \& Haden, 1997), e aos três anos, em comparações aqui/na minha casa (Umiker-Sebeok, 1979). Peterson (1990) diz que crianças entre dois e três anos não fornecem espontaneamente elementos de 
orientação (Quem? Onde? Quando?), e que o auxílio de adultos ensina a elas o que devem incluir na narrativa, e isso é progressivamente internalizado. Como refere McCabe (1996), é na conversação dialógica das crianças com seus pais e pessoas próximas que elas começam a produzir suas narrativas monológicas. $\mathrm{O}$ apoio dos adultos e de outras crianças vai completando e dando contornos à narrativa verbal infantil, pela atenção dispensada, pelas perguntas e comentários que são feitos, pelos olhares e expressões trocados. Os resultados dessas pesquisas parecem confirmar a tese walloniana fundamental de que o desenvolvimento parte do sincretismo para uma progressiva diferenciação e individuação.

Pesquisas longitudinais (Fivush \& Haden, 1997; Perroni, 1992) e transversais (Costa Silva, 2000; Ilgaz \& Aksu-Koç, 2005; Umiker-Sebeok, 1979) têm mostrado de forma consistente avanços significativos na narrativa de crianças entre três e cinco anos de idade. As histórias pessoais vão se tornando mais longas e organizadas, proporcionando ao interlocutor informações sobre lugar e personagens. Estas informações tendem a se concentrar no início da narrativa, perto dos cinco anos. Para criar e recontar histórias de ficção as crianças costumam necessitar por mais tempo do auxílio de parceiros e material de apoio, como livros, gravuras e brinquedos. Este tipo de habilidade associa-se à experiência de socialização familiar envolvendo histórias ficcionais (Heath, s.d.), que depende freqüentemente da condição socioeconômica da família. (Shiro, 2003). As crianças aprendem progressivamente a usar narrativas em suas múltiplas funções, para manter a atenção do outro, enganá-lo, convencê-lo a fazer o que desejam, negociar regras. Além de uma narrativa mais completa em sua estrutura, e de utilizar uma maior variedade dos tipos de elementos estruturais, começam a fazer comentários avaliativos e reflexões sobre as coisas que contam, principalmente após os cinco anos. Isto é, a avaliação vai passando a ser explicitada verbalmente, seja pela criança ao falar do seu ponto de vista, seja através de personagens das histórias. Outro aspecto fundamental é a performance narrativa que vai se desenvolvendo, a capacidade de utilizar recursos expressivos corporais, afetivos e verbais para manter a atenção da platéia e envolvê-la no que está sendo contado. Tudo isso representa uma expansão significativa dos meios de que a criança dispõe para a auto-afirmação e negociação social, fundamentais na etapa personalista. Entretanto, é importante frisar que cada aspecto do desenvolvimento da narrativa (estrutura, seqüencialidade, avaliação e performance) é profundamente influenciado pela cultura imediata que envolve a criança, a família e comunidade, por suas maneiras de narrar e de oportunizar as narrativas infantis, o conteúdo e forma de suas histórias, os valores transmitidos através delas.

Entre os quatro e os cinco anos, com o surgimento de uma "voz narrativa" (Perroni, 1992), o interlocutor adulto passa a ter um papel menos ativo, e a criança vai começando a evidenciar maior autonomia para narrar. Conforme Costa Silva (2000), a criança vai se constituindo como ser do discurso (locutor ou narrador) e como autor, responsabilizando-se pela organização do discurso narrativo e avaliando o que é narrado. Um pouco antes dos seis anos observou-se (Costa Silva, 2000) uma unificação plurifuncional da voz da criança, que organiza a narrativa em torno de três vozes: autor (sujeito da experiência, que comenta e reflete), narrador (aquele que conta o que se passou) e personagens (múltiplas vozes distintamente apresentadas na narrativa). Todo esse processo, conforme Wallon (1934/1995), pode ser entendido como a manifestação de certa estabilização do sentido de si mesmo pela criança, diferenciando-se das demais pessoas e personagens envolvidos em sua vida e podendo então se lançar às tarefas de definir e explicar.

\section{CONSIDERAÇÕES FINAIS}

Mesmo considerando-se algumas diferenças entre conceitos wallonianos e os estudos sociolingüísticos sobre narrativa, é possível estabelecer uma complementaridade entre ambas as perspectivas. $\mathrm{O}$ discurso narrativo pode ser entendido como um contexto onde a criança consegue realizar o trabalho intelectual envolvido no sincretismo da etapa personalista com maior espontaneidade, organizando a experiência em perspectiva e colocando a realidade em diferentes dimensões, conforme uma necessidade narrativa, antes de conseguir fazê-lo a partir de uma necessidade lógica. Embora certamente não seja uma condição suficiente para que a criança desenvolva $o$ pensamento categorial, seria uma condição anterior e necessária para ele. Além disso, a narrativa possui a dimensão de jogo, descrita por Wallon como combinação funcional de realidade e fantasia que trabalha com o mundo das possibilidades, 
proporcionando um contexto para que também o pensamento discursivo sincrético se desenvolva. Esta seria uma condição necessária à evolução da imaginação criadora.

Ao mesmo tempo em que é adquirida e estruturada a partir de convenções culturais, a narrativa é um instrumento especialmente rico para a diferenciação da criança como um indivíduo, na etapa personalista, por muitas razões. A criança escuta e gradativamente produz histórias sobre personagens com suas intenções e desejos, que se confrontam com circunstâncias e têm de negociar com elas, o que proporciona elementos de identificação e uma relação entre pessoas e seus contextos. Como instrumento de negociação cultural, a narrativa possibilita à criança lidar melhor com o conflito entre precisar do outro e diferenciar-se dele, desenvolvendo meios de sedução e persuasão, aprendendo a situar e envolver o outro naquilo que conta. Além disso, ocorre na narrativa a organização de várias dimensões do "eu": o eu que experimenta, sente e avalia aqui e agora, o que relata os eventos e ações, e o que empresta sua voz aos personagens. Tudo isso age simultaneamente para o fortalecimento do sentido de si mesmo da criança e para o enriquecimento das suas possibilidades expressivas e identificatórias.

A narrativa situa-se, então, numa intersecção entre a dimensão afetiva e cognitiva da relação que a criança estabelece com o complexo mundo onde tenta se situar e que procura explicar. Presente nas brincadeiras de faz-de-conta, passa gradativamente a se desenvolver na linguagem verbal, ampliando suas possibilidades de referência, suas formas e funções. As implicações educacionais de tudo o que foi discutido são evidentes, quanto à necessidade de apoiar narrativamente o período de transição da atividade lúdica e do pensamento sincrético, predominantes na infância, para as demandas afetivas e cognitivas da aprendizagem escolar e da socialização das crianças mais velhas (Baumer, Ferholt, \& Lecusay, 2005).

\section{REFERÊNCIAS}

Bastos, A. I. (2003). A construção da pessoa em Wallon e a constituição do sujeito em Lacan. Petrópolis: Vozes.

Baumer, S., Ferholt, B. \& Lecusay, R. (2005). Promoting narrative competence through adult-child joint pretense: Lessons from Scandinavian educational practice of playwold. Cognitive Development, 20, 576-590.

Brockmeier, J. \& Harré, R. (2003). Narrativa: problemas e promessas de um paradigma alternativo. Psicologia: Reflexão e Crítica, 16(3), 525-535.
Bruner, J. (1991). The narrative construction of reality. Critical Inquiry, 18, 1-21.

Bruner, J. (1997). Atos de significação (S. Costa, Trad.). Porto Alegre: Artes Médicas. (Original publicado em 1990).

Bruner, J. (1998). Realidade mental, mundos possiveis (M. A. Domingues, Trad.). Porto Alegre: Artes Médicas. (Original publicado em 1986).

Bruner, J. (2000). A cultura da educação (M. A. Domingues, Trad.). Porto Alegre: Artes Médicas. (Original publicado em 1996).

Costa Silva, C. L. (2000). O desenvolvimento da figura enunciativa do locutor na narrativa infantil. Em F. Indursky \& M. C. Campos (Orgs.), Discurso, memória e identidade (pp. 287-295). Porto Alegre: Sagra Luzzatto.

Dantas, H. (1990). A infância da razão. São Paulo: Manole.

Dunn, J. (1988). The beginnings of social understanding. Cambridge: Harvard University.

Feldman, C. F. (2005). Mimesis: Where play and narrative meet. Cognitive Development, 20, 503-513.

Fivush, R. \& Haden, C. (1997). Narrating and representing experience: Preschoolers' developing autobiographical accounts. In P. Van den Broek, P. Bauer \& T. Bourg (Eds.), Developmental spans in event comprehension and representation: Bridging fictional and actual events (pp.169-198). New Jersey: Laurence Erlbaum Associates.

Griffin, T., Hemphill, L., Camp, L. \& Wolf, D. (2004). Oral discourse in the preschool years and later literacy skills. First Language, 24(2), 123-147.

Heath, S. (s.d.). What no bedtime story means: Narrative skills at home and school. In A. Duranti (Ed.), Linguistic Antropology: A reader (pp. 318-342).

Ilgaz, H. \& Aksu-Koç, A. (2005). Episodic development in preschool children's play-prompted and direct-elicited narratives. Cognitive Development, 20, 526-544.

McCabe, A. (1996). The structure of stories and how that develops. In A. McCabe, Teaching children to appreciate all kinds of good stories (pp. 25-43). New York: McGraw Hill.

Melzi, G. (2000). Cultural variations in the construction of personal narratives: Central american and european american mothers' elicitation styles. Discourse Processes, 30(2), 153-177.

Michaels, S. (1986). Narrative presentations: An oral preparation for literacy with firsts graders. In J. CookGumperz (Ed.), The social construction of literacy (pp. 94116). Cambridge: University.

Nelson, K. (2000). Narrative, time and the emergence of the encultured self. Culture and Psychology, 6(2), 183-196.

Perroni, M. C. (1992). O desenvolvimento do discurso narrativo. São Paulo: Martins Fontes.

Peterson, C. (1990). The who, when and where of early narratives. Journal of Child Language, 17, 433-455.

Ricoeur, P. (1980). Narrative Time. In W. Mitchell (Ed.), On Narrative (pp.165-186). Chicago: University.

Sawaya, S. (2001). A infância na pobreza urbana: linguagem oral e a escrita da história pelas crianças. Psicologia $d a$ USP, 12(1), 153-178. 
Shiro, M. (2003). Genre and evaluation in narrative development. Journal of Child Language, 30, 165-195.

Soares, M. (2002). Linguagem e escola: uma perspectiva social. São Paulo: Ática.

Sperb, T. M. \& Smith, V. H. (2005, junho). The space for narrative construction in the early educational context. In Annual Meeting of Jean Piaget Society. Vancouver, Canadá.

Umiker-Sabeok, D. J. (1979). Preschool children's intraconversational narratives. Journal of Child Language, 6, 91-109.

Vasconcellos, V. M. R. de (1996). Wallon e o papel da imitação na emergência de significado no desenvolvimento infantil. Em M. I. Pedrosa (Org.), Coletâneas da ANPEPP: Investigação da criança em interação (pp.33-47).

Vieira, A. (2001). Do conceito de estrutura narrativa à sua crítica. Psicologia: Reflexão e Crítica, 14(3), 599-608.
Wallon, H. (1947). Del acto al pensamiento: Ensayo de psicologia comparada. Buenos Aires: Lautaro. (Original publicado em 1942)

Wallon, H. (1989). As origens do pensamento na criança. (D. S. Pinheiro \& F. A. Braga, Trads.). São Paulo: Manole. (Original publicado em 1945).

Wallon, H. (1995). As origens do caráter na criança. (H. D. de Souza Pinto, Trad.). São Paulo: Nova Alexandria. (Original publicado em 1934).

Wallon, H. (2000). L'Evolution psichologique de l'enfant. Paris: Armand Colin. (Original publicado em 1941).

Recebido em 15/02/2006 Aceito em 08/04/2007

Endereço para correspondência: Vivian Hamann Smith. Rua Nossa Senhora de Lourdes, 612, CEP 91920-040.Porto Alegre, RS. E-mail: viviansmith@terra.com.br 